\title{
DEVELOPMENT OF A NEW BLASTING VIBROSEIS TECHNIQUE AND ITS APPLICATION TO THE EXPLORATION OF GEOLOGICAL STRUCTURES
}

\author{
Xinzhuang Cui ${ }^{1}$, Zhennong Tian ${ }^{2 *}$, Sheqiang Cui ${ }^{2}$, Qing $\mathrm{Jin}^{2}$ \\ ${ }^{1}$ Shenzhen Institute, Shandong University, Shenzhen 518057, P.R. China \\ ${ }^{2}$ School of Civil Engineering, Shandong University, Jinan 250061, P.R. China
}

(Received: June 2016 / Revised: September 2017 / Accepted: October 2017)

\begin{abstract}
Seismic waves used for exploration of geological structures are mostly generated from blast sources. A new blasting vibroseis apparatus, which utilizes the homogeneity, isotropy, and incompressibility of water to reduce damage to adjacent rock from blast waves, was developed. This method overcomes the low repeatability and low control issues of traditional blast methods (downhole charge) while maintaining the advantages of high explosive power, sharp pulse signal, and a wide range of frequency domains. Blasting vibroseis and traditional blasting tests were implemented in the Three Gorges Reservoir Region, China. The finite element method (FEM) method was used to numerically calculate blasting vibroseis-induced dynamic ground pressures. Through a series of comparison tests, the characteristics of the seismic waves generated by blasting vibroseis were summarized and the repeatability and controllability of the blasting vibroseis test was validated. The blasting vibroseis apparatus was then used to detect geological structures below the surface of the Maoping landslide, China, and the results were very consistent with previous drilling exploration (89\%), which reflects the practical value of the new blasting vibroseis for the exploration of geological structures. Blasting vibroseis can be used as a practical and cost-effective method to detect geological structures.
\end{abstract}

Keywords: Blasting vibroseis; Geological structural exploration; Repeatability; Seismic wave

\section{INTRODUCTION}

Geophysics applies the principles of physics to the study of the earth, which is composed of materials with different physical properties, such as density, acoustic velocity, elastic moduli, electrical conductivity, magnetic susceptibly, and dielectric constants. Measurements can only be taken at or near the earth's surface to reveal where the earth's interior physical properties vary vertically and laterally. Hence, geophysical techniques have been developed to indirectly determine the subsurface framework of an area based on its subsurface physical properties. Geophysical techniques are used almost exclusively for ore deposit prospecting, engineering site investigations, geothermal applications and groundwater; these include magnetic prospecting (Dobrin \& Savit, 1960), electrical prospecting (Smith, 1942), well logging (Segesman, 1980), and radioactive prospecting (Edmundson \& Raymer, 1979). However, seismic wave techniques are the most widely used, accounting for more than half of geological exploration techniques (Dobrin \& Savit, 1960). For all geophysical methods, there must exist an operative physical property to which the method is sensitive; the type of physical property that

\footnotetext{
*Corresponding author's email: tyyx_123@163.com, Tel: +86-531-88364701, Fax: +86-531-88365167 Permalink/DOI: https://doi.org/10.14716/ijtech.v8i5.862
} 
a method responds to determines its range of application. For example, the electrical prospecting method is suitable for locating groundwater tables, because saturated rock can be distinguished from dry rock by its higher electrical conductivity. Similarly, the magnetic prospecting method is suitable for locating buried magnetic ore bodies because of their high magnetic susceptibility. The seismic wave method measures the response of seismic waves, acting as input into the earth, that refract or reflect off subsurface soil and rock boundaries. Longitudinal, transverse, and surface waves are the three basic propagation forms of seismic waves in geological bodies. Their velocities and amplitudes are influenced by the geological body's properties and stratum structures. By collecting this information from seismic waves, in theory, geological structures can be inverted. There are many ways to generate seismic waves, but the blasting method is the most commonly used because of its (1) high power: a small charge can produce seismic waves with high amplitudes, and its quantity can be easily adjusted for different stratum depths; (2) sharp pulse signal: the arrival times of the reflected waves need to be precisely recorded, thereby, sharp pulse signals have more advantages than continuous dull waves; and (3) wide range of frequency domains: different wave lengths distinguish different geological structures, and an adequate range of frequency domains enhances this process.

Traditional blasting methods place blast charges down boreholes. Due to diagenetic process, cracks and joints are common in rocks. Thus, the rocks near the borehole are usually structurally complex and destroyed by high blasting loads. This makes seismic wave propagation uncontrollable, which leads to unrepeatability of traditional blasting tests (Dowding, 1985). Therefore, non-blasting vibroseis methods have been developed, such as hammer vibroseis (Suits et al., 2010), hydraulic drive vibroseis (Sallas, 2010), electromagnetic vibroseis (Sun \& Ling, 2009), and dinoseis (Godfrey et al., 1968). However, although these non-blasting seismic sources make the tests repeatable, their power, signal sharpness, and range of frequency domains are much lower than blasting sources.

In the current study, blasting vibroseis was developed during field testing, and the characteristics of the induced dynamic ground pressures were analyzed. Additionally, comparisons to traditional blasting source tests were used to verify the repeatability and regularity of the blasting vibroseis. Finally, the developed blasting vibroseis technique was used to replicate the detection of geological structures below the surface of the Maoping landslide previously intersected by drillholes.

\section{METHODS}

\subsection{Apparatus}

The blasting vibroseis apparatus was composed of a water container; this was constructed from a framework made of six hoops and twelve vertical, evenly spaced steel reinforcing bars, welded to each other, and wrapped in plastic film. The cage diameter was $0.6 \mathrm{~m}$, the height was $0.8 \mathrm{~m}$, and the container was filled with $0.22 \mathrm{~m}^{3}$ of water (Figure 1). Spackling compound was used as a couplant to connect the container base to the ground. The test charges were emulsion explosives; mixtures of oxidizers and carbonaceous fuels that have excellent water resistance. The density of the emulsion explosive was $1.2 \mathrm{~g} / \mathrm{cm}^{3}$, and each blast vibroseis used $50 \mathrm{~g}$ of emulsion explosive and an electronic detonator suspended $0.2 \mathrm{~m}$ above the base of the container. The explosive container was sphere-shaped with a $45 \mathrm{~mm}$ diameter. The plastic wrapping was disposable so that induced waves in the water could be transmitted into the ground with lower losses. The framework was not damaged by the blast and was reused. Basting vibroseis needs no charge-hole drilling, so it is suitable for the exploration of geological structures in mountainous regions inaccessible to drilling apparatus. Moreover, blast 
vibroseis avoids direct contact between the charge and adjacent rocks, which reduces rock damage, and the influence of induced rock structures on stress waves is mitigated.

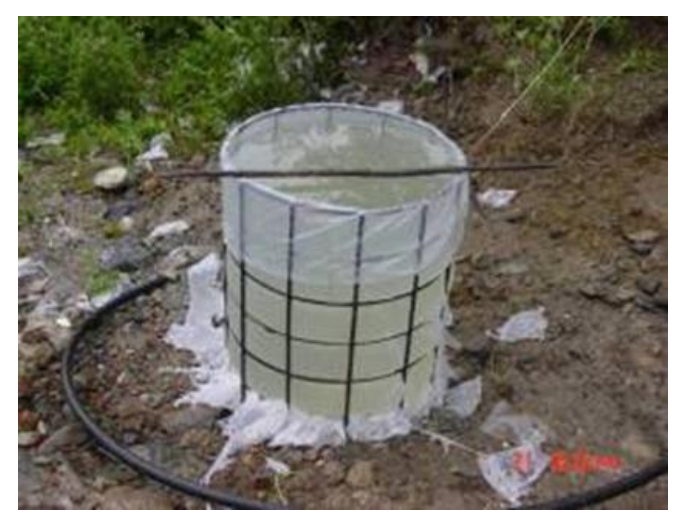

Figure 1 Blasting vibroseis apparatus

\subsection{Blasting Vibroseis-induced Dynamic Ground Pressure}

For a spherical charge in an unlimited water body, the peak dynamic pressures can be expressed as follows (Cole \& Weller, 2009):

$$
\left\{\begin{array}{c}
\Delta P=\frac{355}{R}+\frac{115}{R^{2}}-\frac{244}{R^{s}}, 0.05 \leq \bar{R} \leq 10 \\
\Delta P=\frac{294}{\bar{R}}+\frac{1387}{\bar{R}^{2}}-\frac{1783}{\bar{R}^{3}}, 10<\bar{R} \leq 50
\end{array}\right.
$$

where, for $\bar{R}=R / \sqrt[8]{W} ; R$ is the distance to the charge center; $W$ is the TNT equivalent of the charge; the unit of $\bar{R}$ is $\mathrm{m} / \mathrm{kg}^{1 / 3}$; and $\Delta P$ is the peak dynamic pressure in $\mathrm{kg} / \mathrm{m}^{2}$.

According to Henrich (1987), if $\bar{R}=R / \sqrt[8]{W}$ in Equation 1 is replaced by $\bar{R}=R / \sqrt[3]{2 W}$, Equation 1 can be used for a limited water body, and blasting tests conducted in cylindrical containers have validated this (Wu et al., 2002).

In this study, finite element software, LS-DYNATM (Livermore Software Technology Corp, USA) was used to numerically calculate blasting vibroseis-induced dynamic ground pressures and compare them with the results of Equation 1 as modified by Henrich. Because the upper surface of the blasting vibroseis apparatus was free to the atmosphere and the sides wrapped in plastic, the reflection coefficients of the stress waves on these surfaces were determined as 1.0. The base of the apparatus was in contact with the ground; according to stress wave attenuation theory (Wang, 2005), the reflection coefficient was determined to be about 0.6. The calculation model is shown in Figure 2, where $d$ is the horizontal distance from a point on the base to the center. The air adopts the polynomial equation of state, the water adopts the Mie-Grüneisen equation of state, and the charge adopts the Jones-Wilkins-Lee (JWL) equation of state (50 g of emulsion explosive was simulated as the equivalent of $42 \mathrm{~g}$ of TNT).

\subsection{Controllability Test}

To determine the controllability of the blasting vibroseis, a series of blasting tests were implemented at an open site located in the Three Gorges region, China, where the rock mass is suitable for blasting tests; its lack of complicated geological structures avoided test interference. Tests of traditional blasting sources were conducted for comparison with the blasting vibroseis tests. Boreholes, $0.3 \mathrm{~m}$ deep and $90 \mathrm{~mm}$ in diameter, were drilled and $50 \mathrm{~g}$ of emulsion 
explosive was placed at the bottom of the boreholes. All tests were carried out twice at the same test points that were 15 and $28 \mathrm{~m}$ away from the blasting source center.

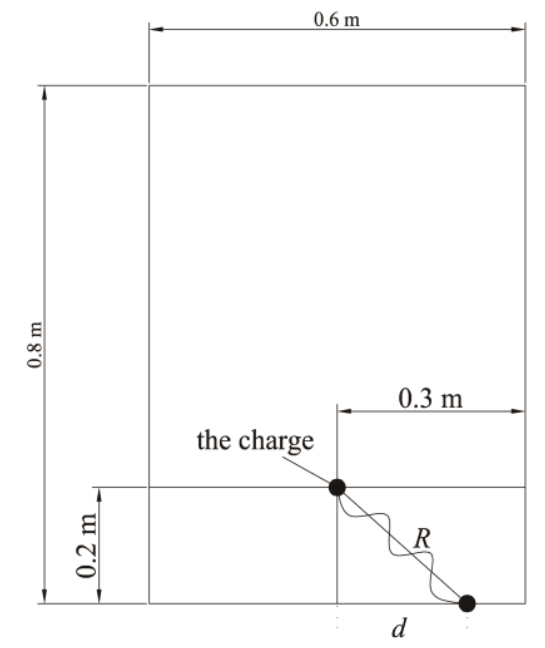

Figure 2 Calculation model for blasting vibroseis

\subsection{Detection of Geological Structure using Blasting Vibroseis Tests}

\subsubsection{Test site conditions}

The Maoping landslide is located on the left bank of the Qing River reservoir, $66 \mathrm{~km}$ downstream from the Geheyan Dam. Its volume is $23.5 \times 10^{6} \mathrm{~m}^{3}$, and it has a longitudinal length of about $1600 \mathrm{~m}$. The front edge of the landslide is cambered and protrudes into the river. The maximum width of the landslide is about $600 \mathrm{~m}$ and in plan view is fan-shaped. Except for the steep front slope $\left(55^{\circ}\right)$, the landslide's average slope is $15^{\circ}-20^{\circ}$, and it is stepped at four levels at altitudes of 225-232, 300-310, 400-420 and 510-520 m, respectively. The Maoping landslide is the most dangerous landslide in the Geheyan reservoir region because its collapse would affect the safety of the Qing River channel and a downstream hydropower station. The landslide and the nearby Three Gorges Dam are located on the same geological stratum group; research of the Maoping landslide is valuable for the construction of the Three Gorges Dam. Drilling exploration has previously been conducted at the Maoping landslide ( $\mathrm{Li}$ et al., 2006). As shown in the geological profile (Figure 3), there is a groove in the toe of the landslide, and the geologic features of each stratum are shown in Table 1.

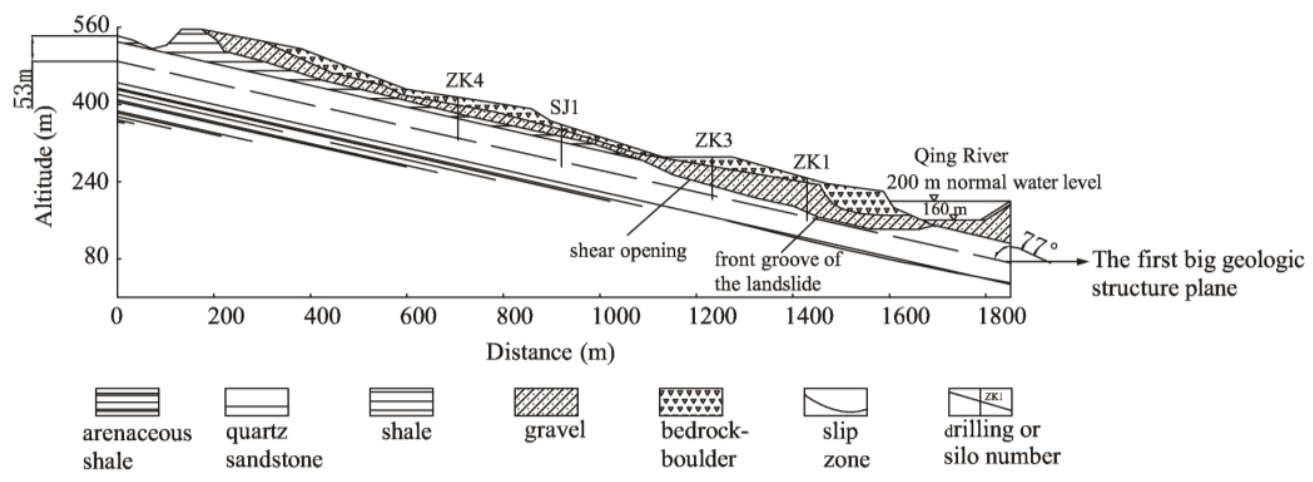

Figure 3 Geological profile of the Maoping landslide

\subsubsection{Test process}

To detect the landslide's geological structures, blasting vibroseis tests were repeated at the same site seven times to obtain sufficient data to locate planar geological structures. In this study, 
four test points (i.e. TP1, TP2, TP3 and TP4 in Figure 4) were included for each time test. During each time test, accelerations at the four test points were recorded; and for different times tests; the positions of the four test points were different. The test points were placed 8-64 m away from the blasting vibroseis center with an interval of $2 \mathrm{~m}$.

Table 1 Maoping landslide stratum

\begin{tabular}{|c|c|c|}
\hline Stratum & Thickness (m) & Features and composition \\
\hline stone, gravel and soil & - & limestone \\
\hline block stone & $20-40$ & flint belt limestone \\
\hline clastic soil & $2-8$ & black carbonaceous shale clastic soil \\
\hline stone and clay & $5-15$ & $\begin{array}{l}\text { variegated quartz sandstone and off-white } \\
\text { dolomite }\end{array}$ \\
\hline gravel & $10-20$ & gray gravel and clay \\
\hline slip belt & $0.20-10.68$ & aubergine clay and quartz sandstone gravel \\
\hline bedrock & - & off-white or aubergine quartz sandstone \\
\hline
\end{tabular}

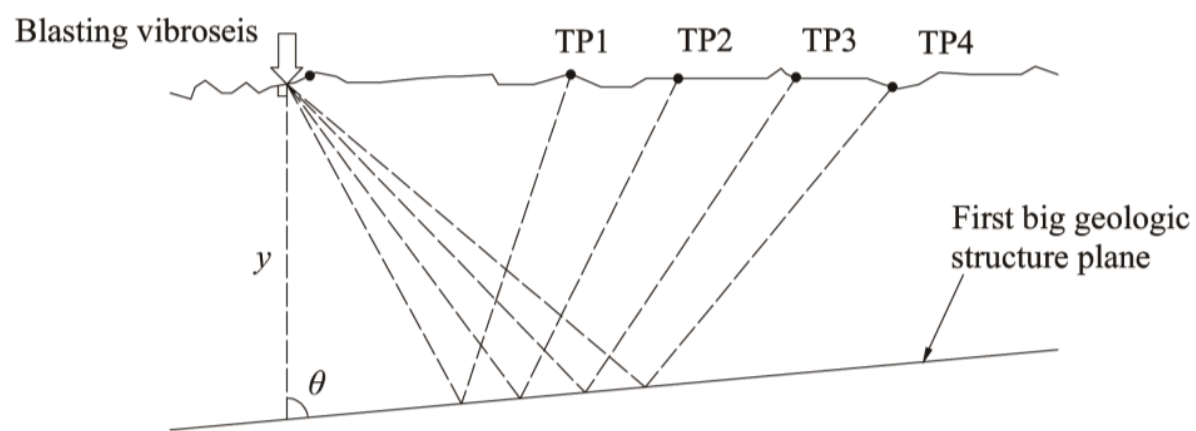

Figure 4 Layout sketch of blasting vibroseis center and test points

\section{RESULTS AND DISCUSSION}

\subsection{Repeatability of Blasting Vibroseis}

Dynamic ground pressure time-histories are shown in Figure 5. The distributions of dynamic ground pressures 15 and $20 \mu$ s after blast initiation are shown in Figure 6. Table 2 shows the peaks of the dynamic ground pressures obtained from the finite element method (FEM) and Henrich's method, respectively. The peaks obtained from Henrich's method are lower than those from the FEM. This is because Henrich's method does not consider the ground reflection effect.

For drilling blasting of coupling charging, peak dynamic borehole wall pressures can be calculated as follows (Liu et al., 2009):

$$
p_{b}=\frac{1}{4} \rho_{c} D^{2} \frac{2 \rho_{r} C_{p}}{\rho_{c} D+\rho_{r} C_{p}}
$$

where, $p_{b}$ is the peak dynamic pressure; $\rho_{c}$ is the density of the charge; $D$ is the detonation velocity; $\rho_{r}$ is the density of the rock; and $C_{p}$ is the velocity of the longitudinal wave.

According to Equation 2, the peak dynamic pressure induced by ordinary emulsion explosive in granite is about $7 \times 10^{4} \mathrm{MPa}(\mathrm{Li} \& \mathrm{Li}, 1992)$. In comparison, the maximum peak dynamic 
ground pressure caused by blasting vibroseis was about 148.20 Mpa (Figure 5). This is far less than the peak borehole wall dynamic pressure calculated from Equation 2. Therefore, blasting vibroseis induced a more uniform distribution of dynamic ground pressure and significantly reduced the damage to surrounding rock; it is controllable and non-damaging, and therefore a repeatable blasting source.

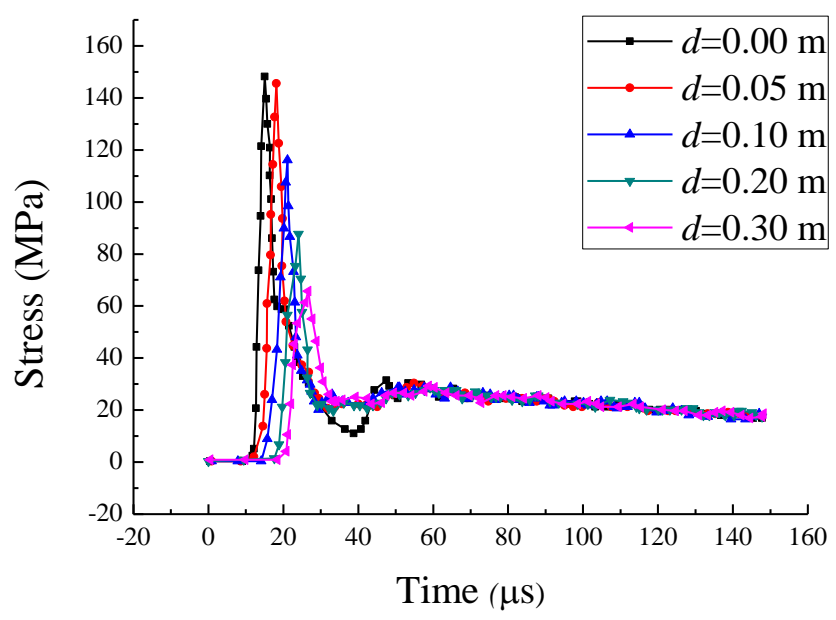

Figure 5 Time-history curves of dynamic ground pressures

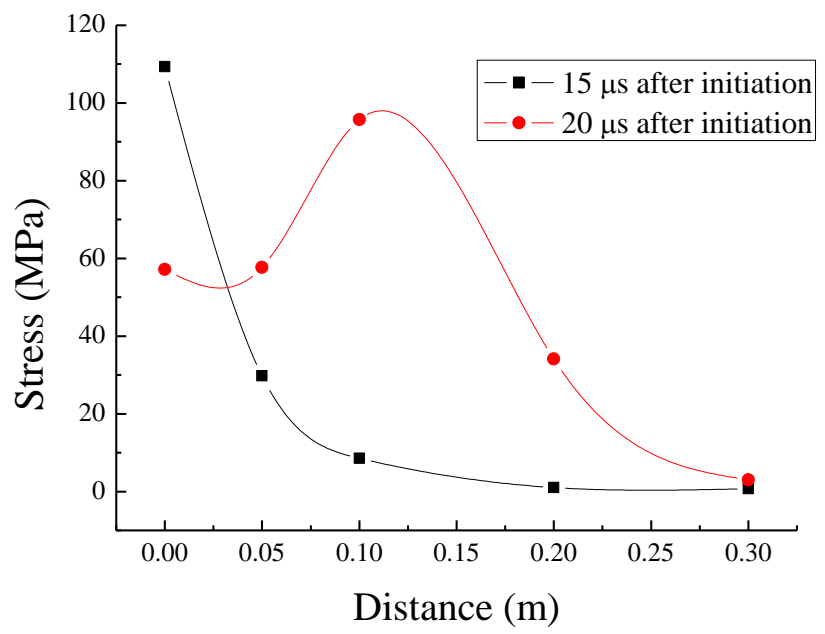

Figure 6 Dynamic ground pressure distributions

Table 2 Peaks of dynamic ground pressures

\begin{tabular}{ccccc}
\hline \multirow{2}{*}{$d(\mathrm{~m})$} & \multirow{2}{*}{$R(\mathrm{~m})$} & \multirow{\mathrm{R}}{*}{$\left(\mathrm{m} / \mathrm{kg}^{1 / 3}\right)$} & \multicolumn{2}{c}{ Peak dynamic pressure (MPa) } \\
\cline { 4 - 5 } & & 0.457 & 152.50 & Henrich's method \\
\hline 0.00 & 0.200 & 0.471 & 146.61 & 127.71 \\
0.05 & 0.206 & 0.511 & 116.07 & 109.57 \\
0.10 & 0.224 & 87.68 & 80.00 \\
0.20 & 0.283 & 0.646 & 65.18 & 58.46 \\
0.30 & 0.361 & 0.823 & & \\
\hline
\end{tabular}

Note: $R=\sqrt{d^{2}+0.2^{2}}, \bar{R}=R / \sqrt[3]{2 W}$ 


\subsection{Controllability of Blasting Vibroseis}

Figures 7 and 8 show the vertical vibration accelerations and frequencies of a test point $15 \mathrm{~m}$ away from the blasting source center for two traditional blasting tests, respectively. Figures 9 to 12 are the vertical vibration accelerations and frequencies of test points 15 and $28 \mathrm{~m}$ away from the blasting source center for two blasting vibroseis tests, respectively. The peak accelerations of the traditional blasting tests decreased by about $25 \%$ in the second test, while the peak acceleration in the blasting vibroseis tests decreased by about 8.3\% (Figures 7-10). The principal frequencies of the two traditional blasting tests at the $15 \mathrm{~m}$ point were about $250 \mathrm{~Hz}$ and $300 \mathrm{~Hz}$ respectively, while in the two blasting vibroseis tests, the principal frequencies remained unchanged. These analyses imply that the test repeatability and controllability of blasting vibroseis is better than that of traditional blasting sources.

Additionally, the peak accelerations generated by the blasting vibroseis were larger than those of traditional blasting sources; the energy dissipation induced by the damage to the surrounding rock was reduced by the blasting vibroseis. Compared to tests of traditional blasting sources, the wave shapes of the blasting vibroseis are simple and distinguishable, which is beneficial for the exploration of geological structures.

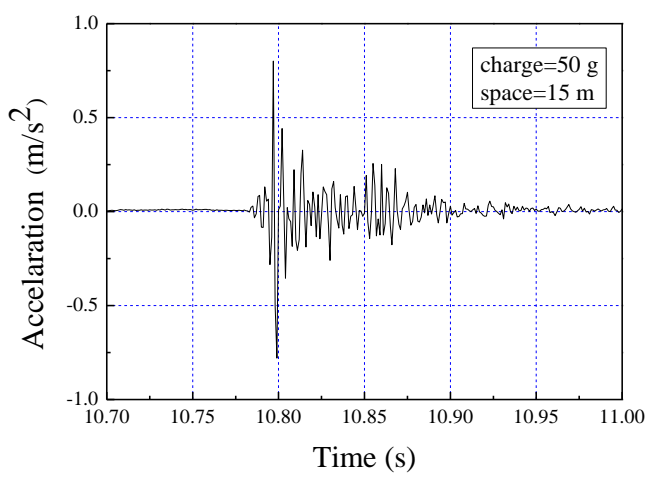

(a) Time-history curve

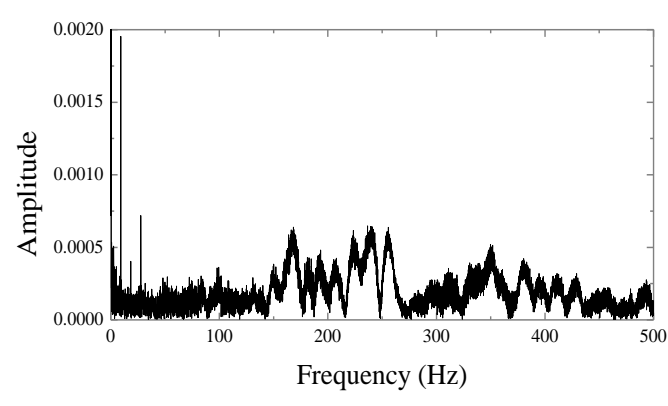

(b) Frequency spectrum

Figure 7 Vertical accelerations of first traditional blasting test $15 \mathrm{~m}$ from the source center

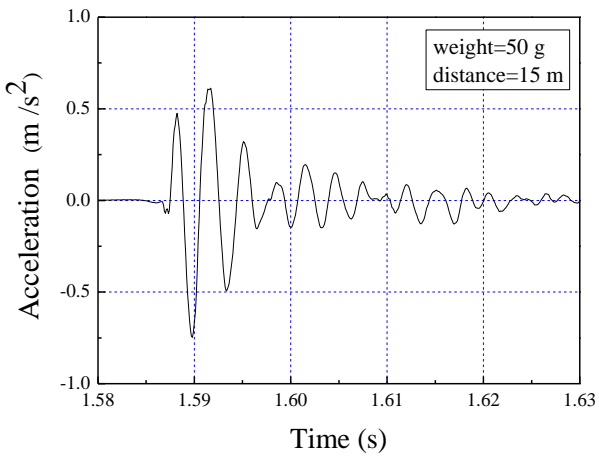

(a) Time-history curve

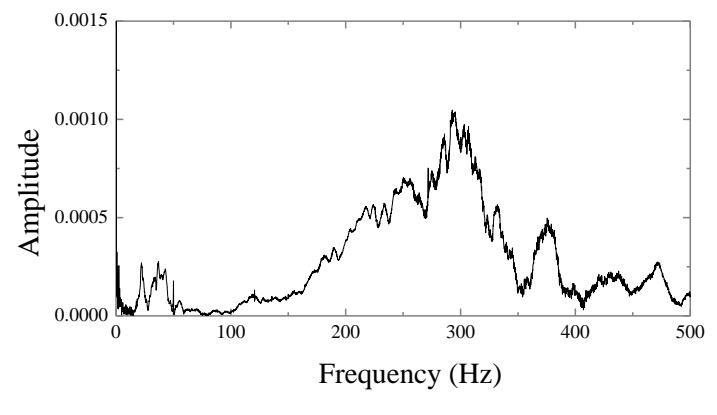

(b) Frequency spectrum

Figure 8 Vertical accelerations of second traditional blasting test $15 \mathrm{~m}$ from the source center 


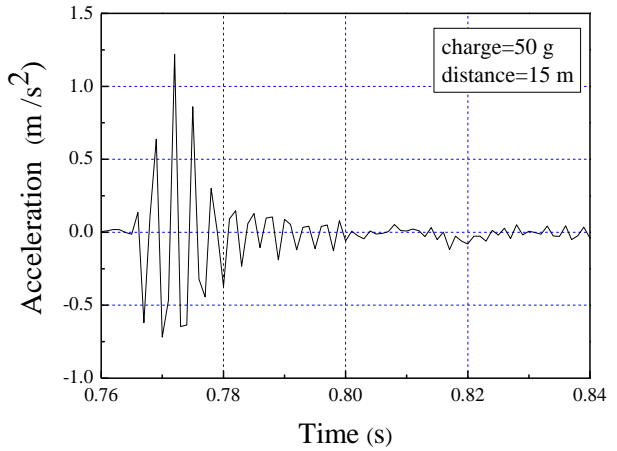

(a) Time-history curve

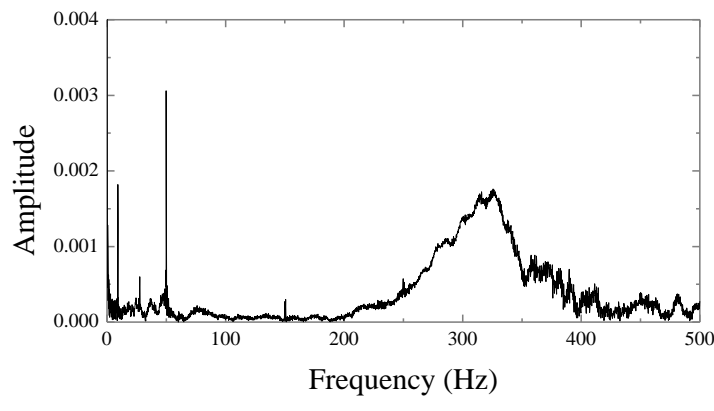

(b) Frequency spectrum

Figure 9 Vertical accelerations of first blasting vibroseis test $15 \mathrm{~m}$ from the source center

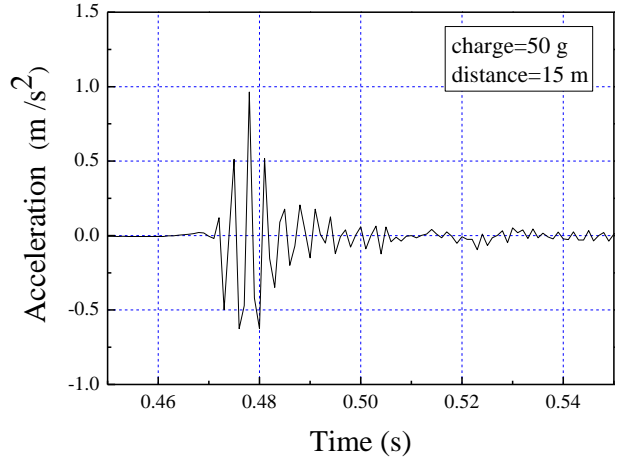

(a) Time-history curve

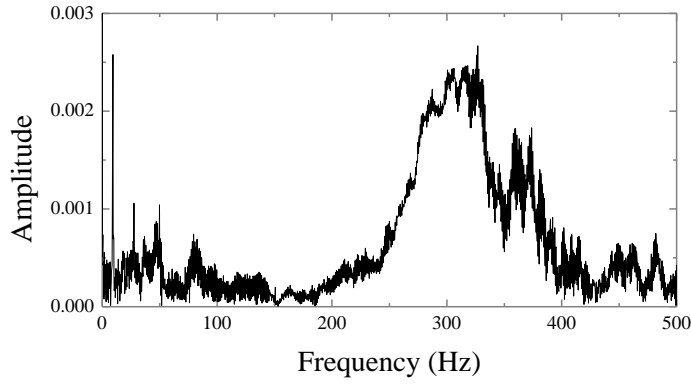

(b) Frequency spectrum

Figure 10 Vertical accelerations of second blasting vibroseis test $15 \mathrm{~m}$ from the source center

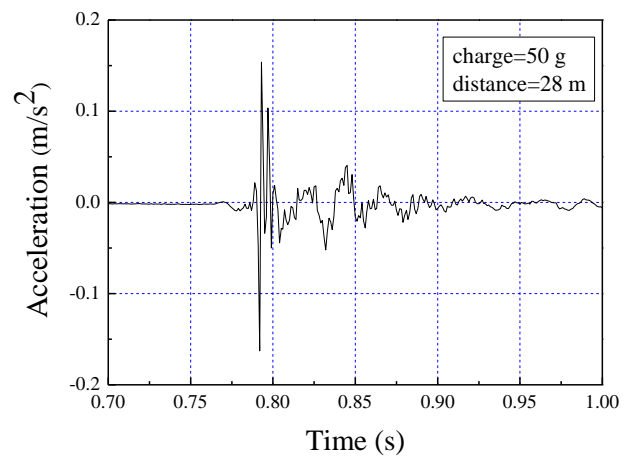

(a) Time-history curve

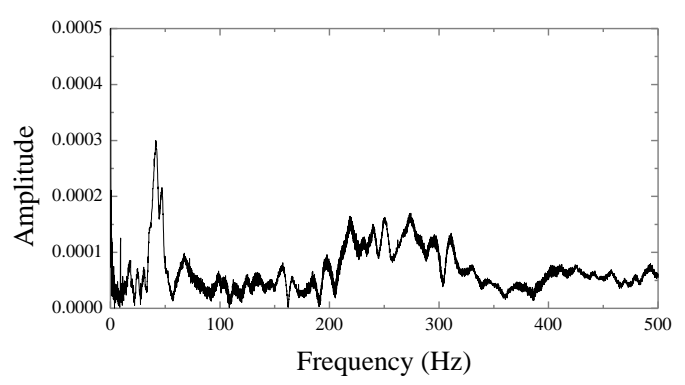

(b) Frequency spectrum

Figure 11 Vertical accelerations of first blasting vibroseis test $28 \mathrm{~m}$ from the source center

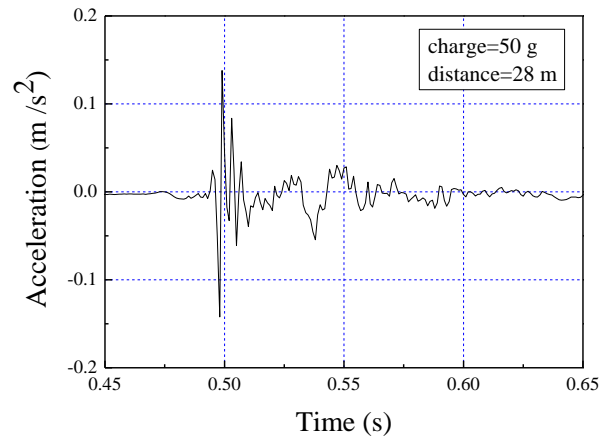

(a) Time-history curve

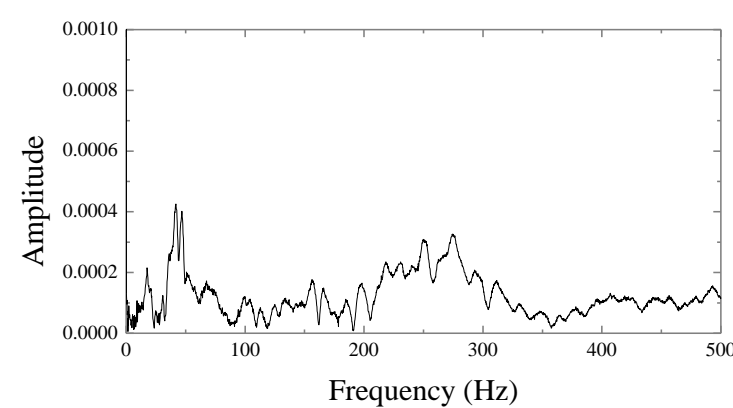

(b) Frequency spectrum

Figure 12 Vertical accelerations of second blasting vibroseis test $28 \mathrm{~m}$ from the source center 


\subsection{Application of Blasting Vibroseis to Exploration of Geologic Structure}

Typical time-history curves of the blasting vibroseis vertical accelerations, including the first breaks and the first reflected waves at 22 and $56 \mathrm{~m}$ are shown in Figure 13. The first reflected wave was induced by the first large planar geological structure. The first reflected waves and the arrival times of the first breaks were obtained from the time-history curves. The data obtained from the test are shown in Table 3.

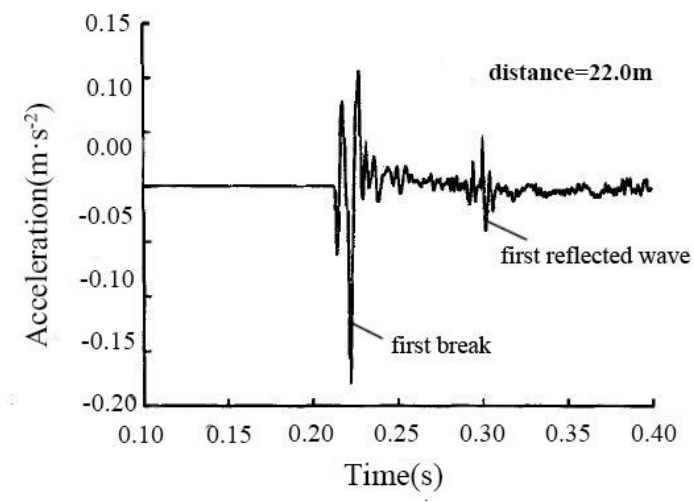

(a)

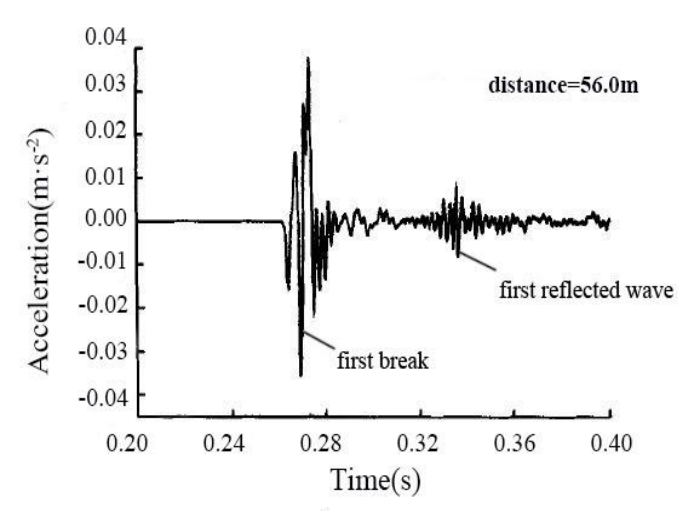

(b)

Figure 13 Typical time-history curves of blasting vibroseis vertical accelerations at 22 and $56 \mathrm{~m}$

Table 3 Initial vibration time (ms) for all test points

\begin{tabular}{crrrrrrr}
\hline $\begin{array}{c}\text { Distance from } \\
\text { blasting } \\
\text { vibroseis }\end{array}$ & $N_{1}=1$ & $N_{2}=2$ & $N_{3}=3$ & $N_{4}=4$ & $N_{5}=5$ & $N_{6}=6$ & $N_{7}=7$ \\
\hline TP1: $8+2 N i$ & 83.48 & 85.33 & 87.62 & 89.72 & 91.86 & 94.02 & 96.20 \\
TP2: $22+2 N i$ & 98.40 & 100.62 & 102.86 & 105.11 & 107.38 & 109.67 & 111.97 \\
TP3: $36+2 N i$ & 114.29 & 116.61 & 118.95 & 121.30 & 123.66 & 126.03 & 128.41 \\
TP4: $50+2 N i$ & 130.80 & 133.20 & 135.60 & 138.00 & 140.42 & 142.85 & 145.23 \\
\hline
\end{tabular}

Assuming that the angle between the first structural plane and a vertical line is $\theta$, the distance from the blasting vibroseis center to the structural plane is $y$, as shown in Figure 3, and the stress wave velocity in the geological body is $c$. According to the geometrical relationships between the test points and the blasting vibroseis center and the arrival times of the first breaks and the first reflected waves, a group of values, $c, y$, and $\theta$, were acquired from every three test points by regression and numerical analysis; there were $C_{28}^{3}$ groups in total. The first 10 groups and the last 10 groups with larger discrete values were removed from the calculation. The calculated average values of the residual groups were: $\bar{y}=47.2 \mathrm{~m}, \bar{\theta}=68.3^{\circ}$, and $\bar{c}=1351.6$ $\mathrm{m} / \mathrm{s}$.

According to the results of the previous drilling exploration (Figure 3), the depth of the first planar geologic structural was about $53 \mathrm{~m}$ and dipping about $77^{\circ}$. The results obtained from the blasting vibroseis tests and the drilling exploration were similar; the accuracy between both results was nearly $89 \%$. Therefore, the results of the blasting vibroseis tests exhibited good consistency with the previous drilling exploration.

\section{CONCLUSION}

A new blasting vibroseis technique was developed for the exploration of geological structures. Compared to drilling exploration that requires expensive equipment, preventing its widespread 
use in field projects, the blasting vibroseis apparatus can be easily installed on the surface and reused. Compared to traditional blasting, damage to adjacent rocks and energy dissipation of seismic waves is significantly reduced. The repeatability of the blasting vibroseis technique was validated by a series of field tests. Blasting vibroseis was then applied to the exploration of planar geological structures below the surface of the Maoping landslide, and the structuralplane parameters obtained were found to be consistent with previous drilling exploration. This demonstrates that blasting vibroseis exhibits good consistency with drilling exploration. Based on this research, blasting vibroseis shows potential for a practical and cost-effective alternative to drilling and blasting for the exploration of geologic structures.

\section{ACKNOWLEDGEMENT}

This work was supported by the Natural Science Foundations of China (Nos. 51778346, 51479105, 51279094), the key research and development program of Shandong Province (2017GGX50102), funds from the Science, Technology and Innovation Commission of ShenZhen Municipality (JCYJ20160429183630760), and the Science Fund for Distinguished Young Scholars of Shandong Province (No. JQ201416).

\section{REFERENCES}

Cole, R.H., Weller, R., 2009. Underwater Explosions. Physics Today, Volume 1(6), p. 35

Dobrin, M.B., Savit, C.H., 1960. Introduction to Geophysical Prospecting, $4^{\text {th }}$ Edition. New York: McGraw-Hill

Dowding, C.H., 1985. Blast Vibration Monitoring and Control. Englewood Cliffs, NJ, USA: Prentice-Hall, pp. 119-126

Edmundson, H., Raymer, L.L., 1979. Radioactive Logging Parameters for Common Minerals. In: Society of Petrophysicists and Well-Log Analysts, $20^{\text {th }}$ Annual Logging Symposium, Volume 20(5), pp. 38-47

Godfrey, L.M., Stewart, J.D., Schweiger, E., 1968. Application of Dinoseis in Canada. Geophysics, Volume 33(1), pp. 65-77

Henrich, J., 1987. Blasting Dynamics and Application. Beijing: Sci. Press, pp. 504-508

Li, J.Q., Li, S.Z., 1992. Mechanics of Explosion. Beijing: Sci. Press.

Li, S.D., Li, X., Liu, Y.H., 2006. Study on Generation and Evolution of Maoping Landslide on Qingjiang River. Chinese Journal of Rock Mechanics and Engineering, Volume 25 (2), pp. 377-384

Liu, Y.C., Wang, X.G., Liu, L.S., Dou, J.L., 2009. An Energy Method for Calculate Borehole Pressure under Decoupled Charging. China Mining Magazine, Volume 18(6), pp. 104-110

Sallas, J.J., 2010. How Do Hydraulic Vibrators Work? A Look Inside the Black Box. Geophysical Prospecting, Volume 58(1), pp. 3-18

Segesman, F.F., 1980. Well-logging Method. Geophysics, Volume 45(11), pp. 1667-1684

Smith, G.A., 1942. U.S. Patent No.2300709. Washington, DC: U.S. Patent and Trademark Office

Suits, L.D., Sheahan, T.C., Cui, X., 2010. Real-time Diagnosis Method of Compaction State of Subgrade during Dynamic Compaction. Geotechnical Testing Journal, Volume 33(4), pp. 299-303

Sun, M., Ling, J., 2009. On Gibb's Phenomenon Supperssion of Correalation Wavelet in a High-resolution Portable Electromagnetic Vibroseis. Journal of Foshan University (Natural Science Edition), Volume 27(3), pp. 9-12

Wang, L.L., 2005. Foundations of Stress Waves, $2^{\text {nd }}$ Edition. Beijing: National Defend Industry Press. 
Wu, D.Y., Li, H.Y., Yang, J.M., 2002. Pressure Measurement and Analysis of a Liquid Cylinder under Different Blasting Cases. Fluid Mechanics Experiment and Measurement, Volume 16(4), pp. 81-91 